\title{
Deciphering Electron Shuttles for Bioremediation and Beyond
}

\author{
Bor-Yann Chen*, Chung-Chuan Hsueh \\ Department of Chemical and Materials Engineering, National I-Lan University, I-Lan, Taiwan
}

Email address:

boryannchen@yahoo.com.tw (Bor-Yann Chen), bychen@niu.edu.tw (Bor-Yann Chen)

${ }^{*}$ Corresponding author

To cite this article:

Bor-Yann Chen, Chung-Chuan Hsueh. Deciphering Electron Shuttles for Bioremediation and Beyond. American Journal of Chemical Engineering. Vol. 4, No. 5, 2016, pp. 114-121. doi: 10.11648/j.ajche.20160405.14

Received: September 23, 2016; Accepted: October 11, 2016; Published: October 17, 2016

\begin{abstract}
Electron shuttles (or redox mediators) are organic chemical(s) that can be reversibly oxidized and reduced to drive electron transport phenomena for energy extraction to support myriads of lives. Efficient energy recycling would provide economically-feasible route(s) to environmental remediation and cost-effective energy shuttling could optimize activities to sustain human health. Thus, using microbial fuel cells (MFCs) as operation strategy is economically-competitive for pollutant bioremediation. Considering reductive decolorization, accumulation of decolorized metabolites (DM) could significantly stimulate electron-transfer (ET) capabilities for dye degradation. In addition, model intermediate(s) with auxochromes (e.g., amino and hydroxyl substituent(s)-containing chemicals) could act as electron shuttles (ESs) to feedback stimulate MFC-assisted degradation. Moreover, quantitative assessment of simultaneous reductive decolorization and bioelectricity generation (SRD\&BG) via MFCs indicated that ET capabilities of SRD\&BG could be augmented more than $40-70 \%$ due to autocatalysis of DM. Apparently, MFC-aided bioremediation was promising to wastewater decolorization due to redox-mediating characteristics of DM. In addition, impedance method in bioelectrochemistry was technically plausible due to specific fingerprints of different genus-related microalgae or microorganisms. As several edible flora (EF) contained crucial compositions to human health (e.g., antioxidants- polyphenolic compounds, flavonoids), extracts of EF were very likely to show promising ET capabilities to augment performance of $\mathrm{RD}$ and/or BG. That is, such stimulating capabilities were possibly associated to antioxidant characteristics of chemical species in EF. Evaluation of ET-stimulating characteristics of EF could thus be an indicator to prescreen whether candidate species of EF could be feasible antioxidant(s) or ESs for human health. As all lives utilize energy as driving force for sustaining diverse metabolic functioning, bioelectrochemistry is evidently vital to the biological world. As UN report mentioned, bioenergy will be a major portion of renewable energy for the planet's energy supply by 2050 . Therefore, ESs would play a significant role of energy extraction not only for environmental remediation, but also human health.
\end{abstract}

Keywords: Electron Shuttle, Dye Decolorization, Bioelectricity Generation, Cyclic Voltammetry, Antioxidants

\section{Introduction}

According to US Environmental Protection Agency, bioremediation as environmentally-friendly treatment is a "treatment that uses naturally-occurring organisms to break down hazardous substances into less toxic or non-toxic substances" by biostimulation and/or bioaugmentation if required. In particular, microorganisms were used as bioremediators for organic degradation (e.g., petroleum biodegradation), cost-effective treatment would be accessible in situ or on site. In fact, regardless of whether reaction time $t$ is short or not, almost all organic matters are subject to biodegradation through aerobic or anaerobic redox reactions (e.g., $t \rightarrow \infty$ for complete recalcitrance). Among organic pollutants, azo dyes contained $-\mathrm{N}=\mathrm{N}$ - azo group(s) as chromophore(s), thus such dyes should be first reductively biodegraded through anaerobic decolorization. However, due to biotoxicity potency of some dyes and derived amine intermediates, apparently biodegradation of dyes would not be taken place; instead dyes were decolorized via biosorption onto cell compartments (e.g., intracellular cytoplasma or cell membrane). However, after serial acclimation or genetic manipulation upon specific microbes, threshold of tolerance 
to textile dyes may be significantly overcome for promising biodegradability. In particular, azo dyes are electron-deficient xenobiotics and capable to be biodegradable via electrophilic azo reduction. That is, cells required capabilities of effective electron transfer to significantly reduce mass transfer resistance between phases for promising reductive decolorization. In fact, to reduce mass transfer resistance, microbial fuel cells (MFCs) are bio-electrochemical devices that use bacteria and mimicking bacterial interactions as biocatalysts to drive current of bioenergy from oxidation of organic matter. Moreover, as one of biomass-based renewable energy, microbial fuel cells (MFCs) could simultaneously expedite reductive decolorization and bioelectricity generation [1], [2] via stimulation of electron transport. However, when dye biodecolorization and bioelectricity generation are taken place in MFC, they are competitive to each other. Thus, exogenous supplementation of electron-shuttling mediator(s) may be crucial to system optimization. As Logan [3] mentioned, "chemical mediators or electron shuttles were routinely added to MFCs that resulted in electron transfer by bacteria and even yeast." In fact, electron shuttles (or redox mediators) are organic chemical(s) that can be reversibly oxidized and reduced to drive electron transport phenomena for energy extraction not only to accelerate contaminant degradation but also to support myriads of lives. Regarding ESs and further aspects, there are two thorough review articles summarizing knowledge on ESs in dechlorination and decolorization and crucial opinions in biotechnology [4], [5]. Brewer [6] and Karaosmanoglu and Kilmartin [7] also provided detailed review articles from various perspectives on natural antioxidants. This study tended to explore the applicability of ES coupled with antioxidants for myriads of aspects with practical values.

\section{Electron Shuttle-Associated Characteristics}

\subsection{Role of Electron Shuttles}

As aforementioned, MFC is bioelectrochemical device to accelerate electron transfer with external circuit as driving force for bioelectricity generation and pollutant degradation. When simultaneous reductive decolorization and bioelectricity generation (SRD\&BG) was taken place after successful acclimation in MFC, organics were oxidized to generate electrons towards electron acceptors (e.g., solid anodic biofilm electrode or suspended azo dye). In fact, Sun et al. [8] and Li et al. [9] first showed technical feasibility of SRD\&BG using mixed cultures (e. g., decolorized $>95 \%$, power density $\sim 600 \mathrm{mM} \mathrm{m}^{-2}$ ). Without dispute, competition of electrons used for color removal and bioelectricity generation will be inevitable in MFC operation. As ESs are organic molecules that can be reversibly oxidized and reduced to drive electron transfer, appropriate supplementation of ES via various modes of operation (e. g., impulse augmentation or dropwise addition in constant or exponential feeding strategy) to manipulate electrons favorably transferred towards RD or BG was feasible. In fact, supplementation strategy of ES is crucial not only to biodegradation, but also to fermentation, in particular for electron transfer-driven processes to generate multiple products. Since electrically steered fermentation can lead to better redox balancing and more complex or reduced products [10], appropriate supplementation of ES could favorably stimulate expression of specific metabolites (e. g., accumulation of polyhydroxybutyrate (PHB), glycerol to 1, 3 propanediol or to ethanol). In fact, due to the metabolic capability of specific microbes in response to electrical conductivity, biological impedance method could be used to screen species of interest among isolated microbial population [11]. That is, with assistance of appropriate ES, maximizing the selectivity of desired product with unwanted metabolite(s) could be achieved. That was why Watanabe et al. [5] indicated that novel biotechnology processes could be developed with the aid of ESs.

\subsection{Mechanisms of Electron Shuttles}

Regarding electron-transport phenomena in MFCs, electrochemical characteristics of microorganisms [3] apparently influenced the performance of bioelectricity generation through at least three mechanisms: electron shuttling cell-secreting mediators (e. g., phenazine, quinones), membrane-bound redox proteins (e. g., cytochromes as mobile electron carriers), and conductive pili (or nanowires) (e. g., wired communities of Geobacter sulfurreducens, Shewanella oneidensis). However, only stimulation of electron-shuttling mediators could be manipulated exogenously as operation strategy from process engineering perspectives, as characteristics of bioelectrochemically-active cells were relatively invariant once master pure or mixed cultures were specifically selected.

Regarding sustainable dye bioremediation, reductive decolorization coupled with MFCs to enhance electron-transporting capabilities was mentioned to be technically promising [12], [13] due to feedback autocatalysis of decolorized metabolites (DMs) of azo dyes (e. g., phenyl methadiamine, 2-aminophenol [14], [15]) as electron shuttles. In fact, DMs could effectively augment electron flux for reductive decolorization and bioelectricity generation (RD\&BG) in MFCs. Watanabe et al. [5] suggested anthraquinone, phenazine, viologen, napthoquinone and cobalamin as basic skeletons of electron shuttles; however, these compounds were evidently chemical structure-complicated and diverse, but not structure-associated to each other [13]. For systematic analysis, Rau et al. [16] disclosed the effect of different quinoid electron shuttles (i. e., hydroxyl (-OH) substitute containing aromatics) on anaerobic dye reduction. Our prior studies also revealed that such decolorized intermediates (i. e., aromatic amines or amino-group (s) containing aromatics) were also electrochemically active redox mediators for dye decolorization. In fact, detailed mechanisms of shuttling characteristics also explained why $-\mathrm{OH}$ and/or $-\mathrm{NH}_{2}$ 
substitute(s) could own electron-mediating capabilities for reversible electron transport [17]. For instance, disubstituted auxochromes containing hydroxyl and/or amino group(s) (e.g., 1,2-diaminobenzene, catechol) [18] were found to be redox mediators for RD\&BG with consideration of chemical structure. As a matter of fact, typical species to reveal electron-shuttling characteristics are active radicals (e.g., hydroxyl or amino-group (s)) and dimerized compounds (e. g., diaminophenazine) for resonance of electrons within aromatic structure(s). However, most of ESs were artificially synthesized, finding natural chemicals with environmental friendliness as ESs would be crucial for practicability.

\subsection{Antioxidants vs. Electron Shuttles}

Regarding hydroxyl group-containing chemicals, catechol group in many polyphenols acts as electron donors scavenging free radicals and active oxygen groups (e.g., scavenging species that initiate peroxidation, quenching $\bullet \mathrm{O}_{2}^{-}$, preventing formation of peroxides [6]) and is therefore responsible for antioxidant activity. Meanwhile, when hydroxyl groups are present on the benzene ring of the compounds (e.g., 2-, 4-aminopheol, hydroquinone (benzene-1,4-diol or quinol)), these molecules can express significant electron-shuttling capabilities for electricity generation [17]. Thus, are hydroxyl (-OH) substituent(s)-bearing electron shuttles also capable to scavenge free radical(s) as antioxidants? Can we find natural chemical(s) with dual capabilities of ES and antioxidant? Aware that an antioxidant is a molecule that inhibits the oxidation of other molecules. In particular, such oxidation is a chemical reaction can generate free radicals, leading to chain reactions that may change cells (refer to https://en.wikipedia.org/wiki/Antioxidant for definition).
That is, some antioxidants may absorb oxygen and most of antioxidants will act as reductants to be oxidized by oxygen, free radicals or other oxidants. In contrast, electron shuttles (ESs) are essential components that can be reversibly transformed between oxidized and reduced forms as "catalysts" to mediate intracellular electron transfer. Meanwhile, microbes also utilize self-produced and naturally present ESs (e.g., decolorized intermediates) for electron transfer to reduce extracellular pollutant(s) threatened to cell survival (e. g., azo dye) [19]. Evidently, ES plays a crucial role for bioenergy metabolism by facilitating electron transfer between microbes, from electron-donating substances to microbes, and/or from microbes to electron-accepting substances [5]. That is, the molecules with redox mediating properties own the catalytic capabilities on redox reaction(s) [4]. Moreover, ESs (or redox mediators; RMs) can be applied to redox reaction(s) of pollutants to enhance the efficiency of detoxification and degradation of diverse inorganic and organic contaminants coupled with appropriate microbial treatment methods. In particular, although electrophilic contaminants (e.g., azo dyes, nitroaromatics, and halogenated aliphatics/aromatics with electron-withdrawing group (EWG)) were unaffected during aerobic wastewater treatment, RM could donate electrons towards contaminants for anaerobic bioreductive reaction to enhance degradation performance [20] (i.e., RHS of reduced/oxidized RM couple in Fig. 1). Meanwhile, these EWG-bearing contaminants would accept electron(s) from RMs to be re-oxidized as ES. Thus, it was suspected that aerobic environments may be a necessary condition for antioxidants to be triggered for reaction(s). Antioxidants may possibly be ESs with appropriate electron donor(s) and acceptor (s) under feasible anaerobic or proper conditions (e.g., epicatechin, catechin; [21]).

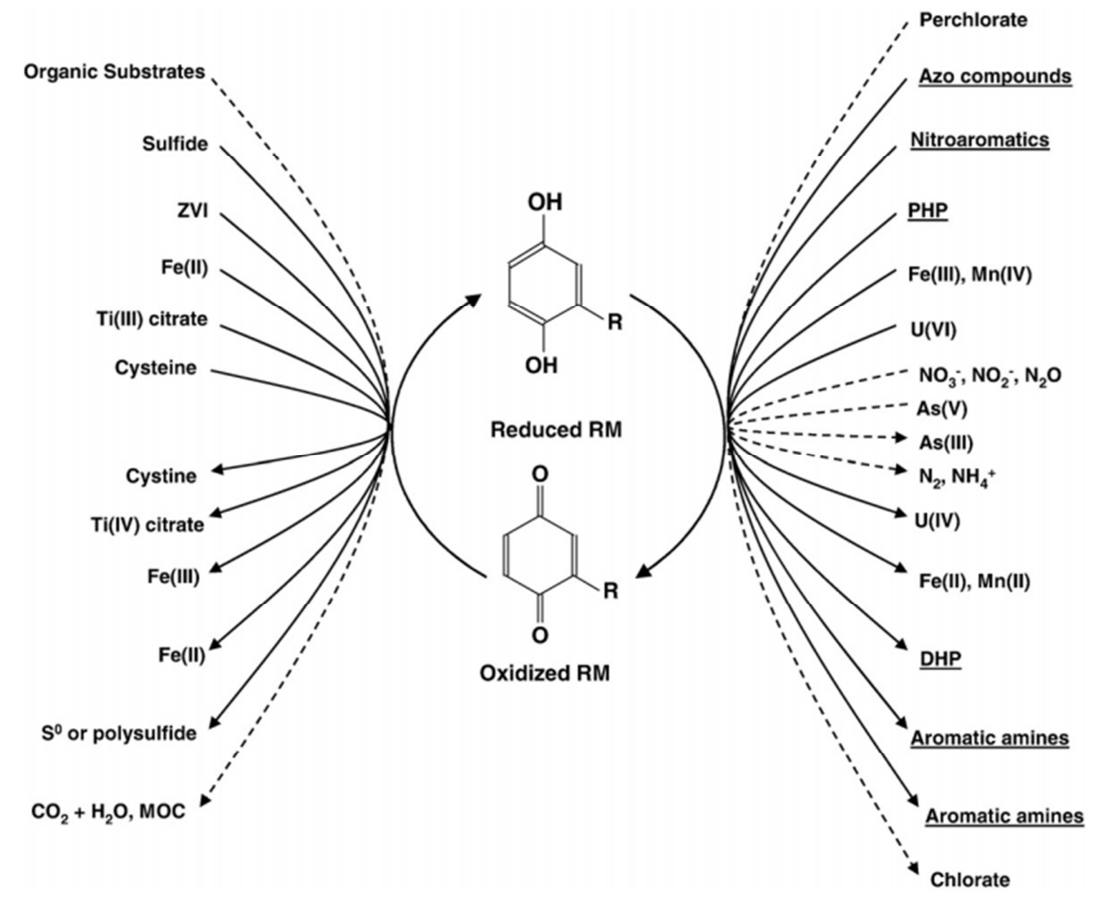

Figure 1. Abiotic (solid lines) and microbial (dashed lines) reactions involved in the reduction and oxidation of electron shuttles (e.g. quinones) (Details cited from Van der Zee and Cervantes [4]). 
Regarding functioning of RM, RM can act as the reductant (i.e., electron donor) to reduce electrophilic pollutants, and then it be reduced by the other reductant (i.e., $\mathrm{NAD}(\mathrm{P}) \mathrm{H})$ in microorganisms at anaerobic condition (i.e., LHS of reduced/oxidized RM couple; Fig. 1). When microbial oxidation of organics (e.g., electron donor- carbohydrates, $\mathrm{H}_{2}$ ) was taken place under anaerobic conditions [22], it generated electrons to support the humic substances (i.e., compounds with quinone, phenol, catechol and sugar moieties) and the quinoid analogues as RMs to be reduced. Meanwhile, reduced quinones can also serve as electron donors to support the microbial reduction of perchlorate, arsenate, nitrate, nitrite and nitrous oxide [23], [24] (i.e., RHS of reduced/oxidized RM couple in Fig. 1).

In addition, several electron shuttles, such as sulfonated quinones (AQS, AQDS), ubiquinone, lawsone, juglone, menadione, $\mathrm{NAD}(\mathrm{P}) \mathrm{H}$, (cyano) cobalamin, phenazine, neutral red, methyl viologen, benzyl viologen, riboflavin, FAD, and FMN were also applicable during the redox (bio)transformation of pollutants.

Table 1. Redox mediators for azo dye reduction by bacteria or cell free extracts from anaerobic azo dye reduction ${ }^{a}$.

\begin{tabular}{|c|c|}
\hline Redox mediator & ${ }^{\mathbf{b}} \mathbf{E}_{0}{ }^{\prime}$ \\
\hline Methyl viologen & -440 \\
\hline Benzyl viologen & -360 \\
\hline Riboflavin & -208 \\
\hline FAD & -219 \\
\hline FMN & -219 \\
\hline Phenosaphranin & -252 \\
\hline Menadione & -203 \\
\hline Janus Green B & -225 \\
\hline AQS (anthraquinone-2-sulphonate) & -218 \\
\hline AQDS (anthraquinone-2,6-disulphonate) & -184 \\
\hline 2-hydroxy-1,4-naphthoquinone & -139 \\
\hline
\end{tabular}

${ }^{\text {a }}$ After Van der Zee, F.P. [25]

${ }^{\mathrm{b}}$ Reduction potential (unit in $\mathrm{mV}$ )

${ }^{\mathrm{c}} \mathrm{RMs}$ functioned as electron donor

In fact, prior studies [14],[15],[17],[18] indicated that benzene derivatives with the different substituents (e.g., sulfonic group $\left(-\mathrm{SO}_{3} \mathrm{H}\right)$, carboxylic group (-COOH), hydroxyl group $(-\mathrm{OH})$, amino group $\left(-\mathrm{NH}_{2}\right)$, thiol group $(-\mathrm{SH})$ ) on benzene ring or the isomers of these derivatives resulted in diverse electron mediating properties. The benzene derivatives could own the redox mediators when two substituents such as hydroxyl group (-OH) or amino group $\left(-\mathrm{NH}_{2}\right)$ on benzene ring located ortho- or para- position with each other [17], [18]. For example, as Chen et al. [26] revealed, the reversible redox properties of $2 \mathrm{AP}$ and $4 \mathrm{AP}$ were due to the reasons as follows: The electron shuttle can be reversibly interchanged between its reduced and oxidized form for mediating electron-transfer processes involved in energy production. For example, the inter-conversion of hydroquinone (p-dihydroxybenzene; a reduced form) and quinone (cyclohexa-2,5-diene-1,4-dione; an oxidized form) through the formation of active radicals (e.g., RD2 and resonance forms RD1A, RD1B in Fig. 2 of ref. [26]) can be reversibly reoxidized and re-reduced. In addition, due to acidic characteristics of hydroxyl groups $(-\mathrm{OH})$ of phenols, the acidic hydrogen can be dissociated to obtain phenolate anions, and then phenolate anions will be favorably oxidized to form active radicals (e.g., RD1A, RD1B, and RD2 in Fig. 2 of ref [26]). Apparently, these steps of free-radical formation are crucial steps to generate redox mediators to mediate electron-transfer processes for energy and/or electricity production. In addition, many derivatives of naphthoquinones or anthraquinones with the free-radical forming characteristics were also capable to be redox mediators. Moreover, isomeric 1-amino-2-naphthol, 4-amino-1-naphthol (i.e., decolorized intermediates of azo dyes - orange I and II; $1 \mathrm{~A} 2 \mathrm{~N}, 4 \mathrm{~A} 1 \mathrm{~N}$ ) also showed significant electron shuttling properties of bicyclic aromatics-mediators due to relatively smaller energy gap between HOMO (highest occupied molecular orbital) and LUMO (lowest unoccupied molecular orbital) of the compounds than benzoquinones [27]. As a matter of fact, as revealed by Rau et al. (i.e., Fig. 5 in ref. [16]), it was expected that electron shuttling capabilities of anthraquinones (AQS, AQDS) seemed to be better than naphthoquinones and benzoquinones. However, it may still depend upon the characteristics of bacterial strains (e.g., extracellular, intracellular or membrane-bound redox enzyme systems, toxicity tolerance). In addition, redox mediating-properties of thionin, malachite green [28] and decolorized metabolites of azo dyes [29] were quantitatively evaluated through comparison of the efficiency of reductive decolorization and bioelectricity generation in MFCs.

In general, the redox mediators may display reversible waves in cyclic voltammetry (CV) (detailed definition refers to https://en.wikipedia.org/wiki/Cyclic_voltammetry as shown below). The difference between the two peak potentials $\left(\mathrm{E}_{\mathrm{pa}}, \mathrm{E}_{\mathrm{pc}}\right) \Delta \mathrm{E}_{\mathrm{p}}$ is of particular interest as $\Delta E_{\mathrm{p}}=\mid E_{\mathrm{pc}}$ $E_{\mathrm{pa}}$, indicating the difference mainly resulted from the effects of analyte diffusion rates. For the ideal case of a reversible one electron-couple, $\Delta E_{\mathrm{p}}$ is $59 \mathrm{mV}$, but typical values observed experimentally are greater (ca. 70-80 mV). If the current is of concern, reversible and irreversible couples are 
usually characterized by $i_{p a} / i_{p c}=1$ and $\neq 1$, respectively (or the ratio of cathodic peak area $\left(\mathrm{S}_{\mathrm{c}}\right)$ to the anodic peak area $\left(\mathrm{S}_{\mathrm{a}}\right)=1$ and $\neq 1$; [30]) (Fig. 2, 3). Many redox processes observed by $\mathrm{CV}$ are quasi-reversible or non-reversible. Deviations from unity are very likely due to a subsequent chemical reaction that is triggered by the electron transfer for complex processes possibly with isomerization, dissociation, association and so forth. However, the cyclic voltammetry (CV) method qualitatively provided the reducing capacity values of antioxidant spices [31]. For example, isomers of quinones own different redox mediating characteristics (i. e., reversible couple), such as RMs 1,3-dihydroxybenzene (resorcinol or resorcin), 1,2-dihydroxybenzene (catechol or pyrocatechol) and 1,4-dihydroxybenzene (hydroquinone, also benzene-1,4-diol or quinol) [17]. However, polyphenols (i.e., polyhydroxyphenols such as pyrogallol, gallic acid, ellagic acid, tannic acid, tannins, and flavonol derivatives) could only show anodic potential peak(s), they revealed significant antioxidant properties (refer to Fig. 2 in ref [21]).

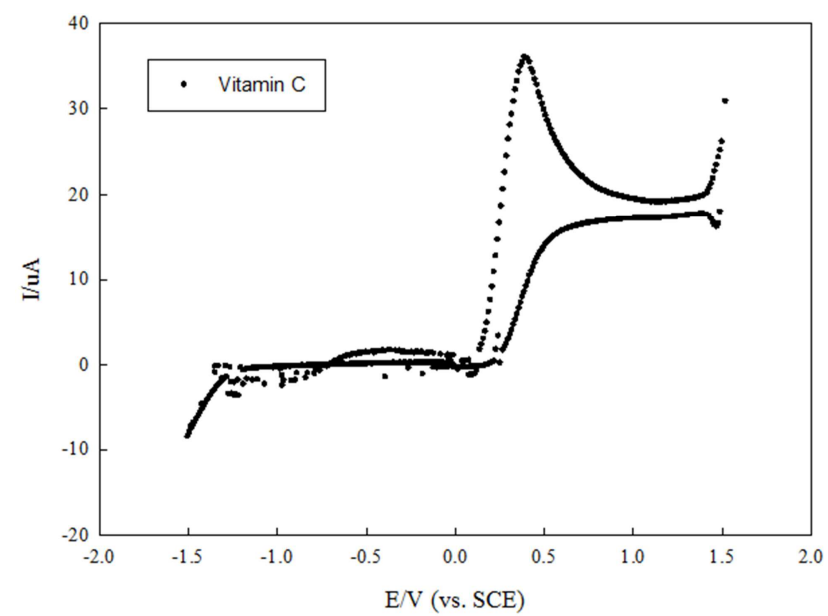

Figure 2. Cyclic voltammogram of vitamin $C$ in $P B S$ solution at scan rate 10 $\mathrm{mV} / \mathrm{s}$, [vitamin C] $=1000 \mathrm{mg} / \mathrm{L}$ (refer to [14] for conditions of measurement) $\left(i_{p a} / i_{p c} \neq 1\right)$.

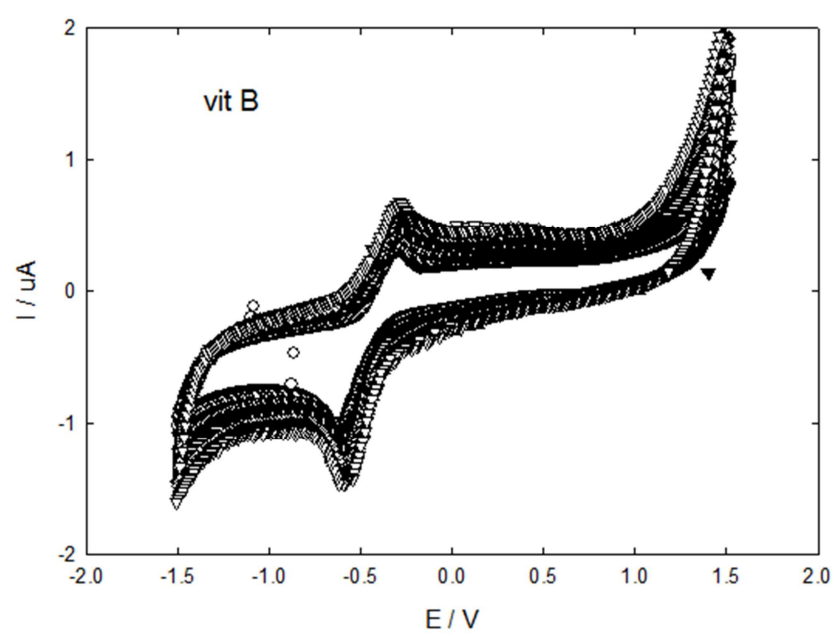

Figure 3. Cyclic voltammogram of riboflavin (vitamin $\mathrm{B}_{2}$ ) in deionized $\mathrm{H}_{2} \mathrm{O}$ solution for 100 cycles at scan rate $10 \mathrm{mV} / \mathrm{s}$, [riboflavin] $=1000 \mathrm{mg} / \mathrm{L}$ (refer to [14] for conditions of measurement) (i.e., reversible couple; $S_{a} / S_{c} \approx 1$ ).

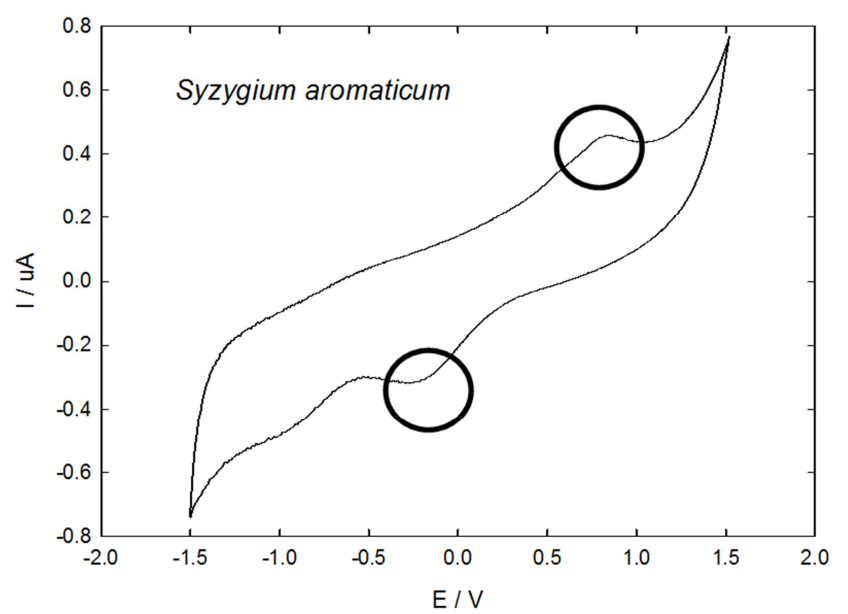

Figure 4. Cyclic voltammogram of clove (Syzygium aromaticum) extract in deionized $\mathrm{H}_{2} \mathrm{O}$ solution at scan rate $10 \mathrm{mV} / \mathrm{s}$, [cloven] $=50 \mathrm{~g} \mathrm{wt} / \mathrm{L}$ (refer to [32] and [14] for sample preparation and conditions of measurement, respectively) (suspected reversible couple with redox potential peaks in circles).

Regarding natural herbs, clove and ginger were typical examples as antioxidants [32] for demonstration. As shown in Fig. 4 and 5, clove (Syzygium aromaticum) was even likely to be ES (i.e., two circles) at specific environmental conditions. In contrast, likely due to inappropriate conditions of measurement for revealing redox electrochemical potentials, ginger (Zingiber officinale) could not clearly show the potential peak as an antioxidant (Fig. 5). These all indicated that if environmental conditions were applicable, antioxidants may also be feasible to be ESs as indicated in $\mathrm{CV}$ profiles. That is, antioxidants and ESs may be equivalent or convertible in appropriate conditions for further practical applications. In addition, as Fig. 3 shown for $\mathrm{CV}$ profiles of riboflavin for 100 cycles, once antioxidants were applicable to be ESs they may be reusable and regenerated in cell compartments. For example, some natural antioxidants may be functioning in oxygen or free radicals-bearing environments, they may be applicable to be ESs in anaerobic conditions (e.g., in gastrointestinal tract). These may provide some options to have further applications in diverse fields not only for environmental biotechnology but also for human health.

\subsection{Criteria of Electron Shuttles and Antioxidants}

If the redox couple is reversible as indicated in $\mathrm{CV}$ profile, during the reverse scan the reduced analyte will start to be re-oxidized, giving rise to a current of reverse polarity (anodic current) to previous conditions. The more reversible the redox couple is, the more similar the oxidation peak will be in shape to the reduction peak. Regarding criteria of effective electron shuttles, the standard redox potential $\left(\mathrm{E}_{0}{ }^{\prime}\right)$ should be between those of the two eventual half reactions (i.e., standard redox potentials of reductants (i.e., electron donors) and oxidants (i.e., pollutants) denoted as $\mathrm{E}_{\text {Reductant }}$ and $\mathrm{E}_{\text {Oxidant }}$, respectively) (i.e., $\mathrm{E}_{\text {Reductant }}<\mathrm{E}_{0}{ }^{\prime}<\mathrm{E}_{\text {Oxidant }}$ ). For example, when the standard redox potentials of quinoid redox mediators $\left(\mathrm{E}_{0}{ }^{\prime}\right)$ 
should be the lower than target dye amaranth, quinoid redox mediators could significantly increase decolorization rate of amaranth [14]. That is, ES seems to act as a "catalyst" that provides an alternative route with lower activation energy for the reaction. In contrast, antioxidants (e.g., thiols and ascorbic acid (vitamin C)) could act as reductants to terminate free-radical producing chain reactions that may damage cells. In fact, there are significant amounts of antioxidants present in natural organisms (e.g., garlic, ginger, black pepper, tea, and grape seed extracts), as plants and animals are living to have complex systems of overlapping antioxidants to protect cells from constant oxidative stress of free radicals, reactive oxygen species, and prooxidants generated [6]. These contained enzymes (e.g., catalase and superoxide dismutase) expressed internally and dietary antioxidants (e.g., vitamin A, C, E, polyphenols, catechol). In particular, low molecular weight antioxidants (e.g., gallic acid, protocatechuic acid) are of great importance in living cells to act as reducing agents to counteract cell-damaging oxidation. As a matter of fact, antioxidant effectiveness is associated to activation energy, rate constants, oxidation-reduction potential, ease with which the antioxidant is lost or destroyed, and antioxidant solubility [6]. Typical examples of -OH-bearing antioxidants are polyphenols and flavonols and their antioxidant activities are greatly increased with more hydroxyl groups introduced (e.g., flavonoids- flavones, flavonols, flavanols, and flavanones). The free radical-scavenging potential of natural polyphenolic compounds seemed to be associated with the number and location of free $-\mathrm{OH}$ groups on the flavonoid skeleton [33]. In addition, typical naturally-growing plants (e. g., spices and herbs) abundant in antioxidants (or redox active compounds) with high oxygen radical absorbance capacity (ORAC) values $(\mu \mathrm{m} \mathrm{TE} / 100 \mathrm{~g})$ are clove $(290283)$, oregano (175295), rosemary (165280), cinnamon (131420) [6].

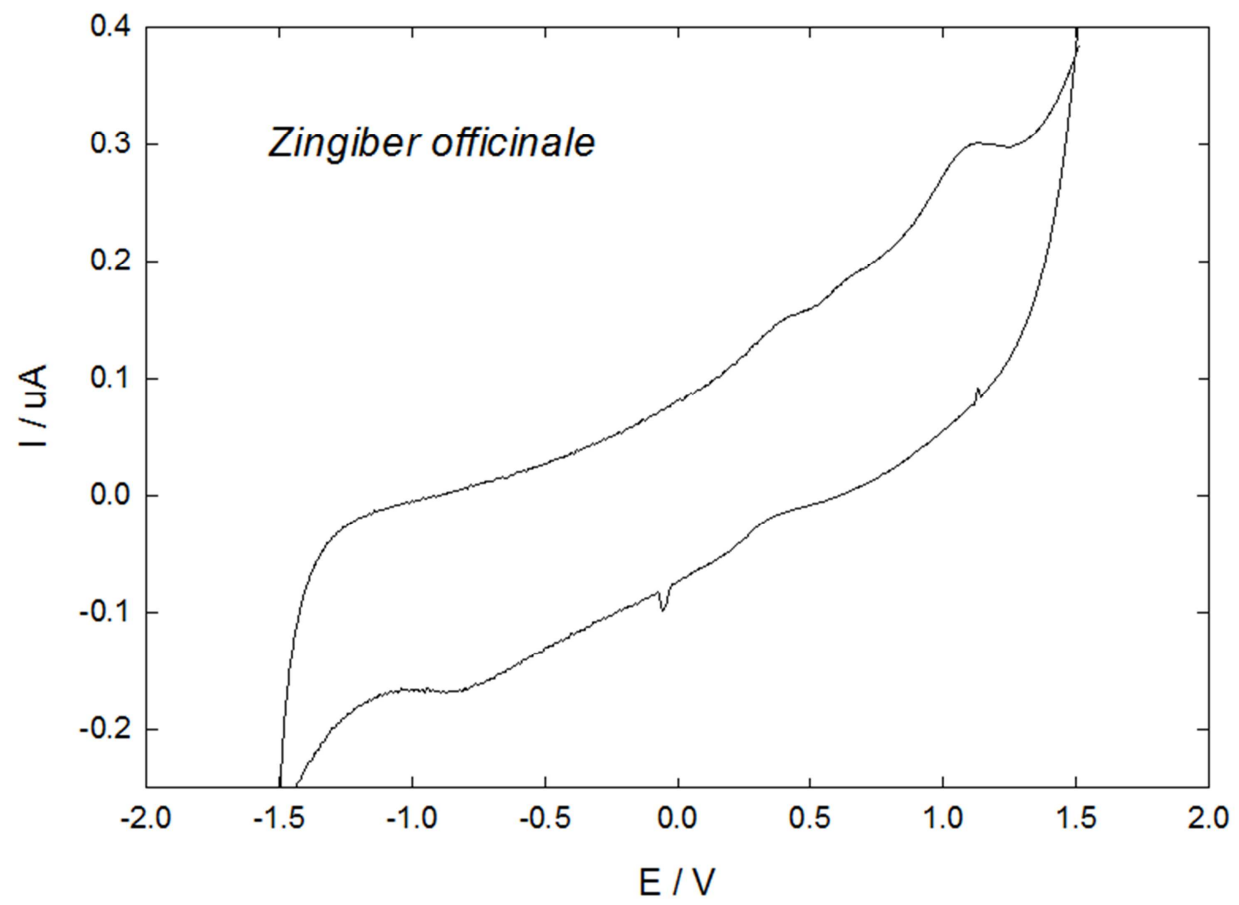

Figure 5. Cyclic voltammogram of ginger (Zingiber officinale) extract in deionized $\mathrm{H}_{2} \mathrm{O}$ solution at scan rate $10 \mathrm{mV} / \mathrm{s}$, [ginger] $=50 \mathrm{~g}$ wt/L (refer to [33] and [14] for sample preparation and conditions of measurement, respectively).

\section{Conclusions and Perspectives}

Electron shuttles play a catalytic role to decrease activation energy and accelerate oxidation rate of organic pollutants. In contrast, antioxidants act as electron donors (or reductants) scavenging free radicals and active oxygen groups. Aerobic environments could be a necessary condition for antioxidants to be effectively functioning. Antioxidants may possibly act as ESs with appropriate electron donor (s) and acceptor (s) at proper anaerobic environments (e.g., $\mathrm{E}_{\text {Reductant }}<\mathrm{E}_{0}{ }^{{ }^{\prime}}<\mathrm{E}_{\text {Oxidant }}$ or $\mathrm{E}_{\text {Microbe }}<\mathrm{E}_{\mathrm{RM}}<\mathrm{E}_{\text {Pollutant; }}$ Fig. 1). This study also showed that antioxidants and ESs may be equivalent or convertible in appropriate conditions for further practical applications.
Therefore, appropriate strategy to switch/manipulate to be catalytic ESs or reductant antioxidants might be of great importance to novel biotechnologies as Watanabe et al. [5] mentioned. ESs and/or antioxidans may provide some options to have further applications in diverse fields not only for environmental biotechnology but also for human health.

\section{Acknowledgements}

Funding supports from Taiwan's Ministry of Science and Technology (MOST) are very much appreciated (MOST-102-2221-E-197-016-MY3, MOST-104-2622-E-197 -006-CC3 and MOST-105-2221-E-197-022). Data analyses of Mr. Jia-Hui Liao, Mr. An-Wei Hsu and Mr. Pei-Lin Yueh 
are very much appreciated. This study ${ }^{\text {sdg }}$ was completed as part of cooperative achievements for Academic Exchange Program between Yan-Tai University (China), Xiamen University (China), Hua-Qiao University (China), Indian Institute of Technology, Madras (India) and National I-Lan University (Taiwan) in 2015-2017. This study was also completed as part of cooperative research association between NIU and Fushan Botanical Garden and Nature Center, Taiwan Forestry Research Institute, Council of Agriculture, Executive Yuan, R.O.C. (Taiwan) (Article \# $1042600316,104 / 05 / 11)$. This study is also dedicated to the memory of Dolloff F. Bishop and Henry Tabak, as most of novel concepts were initiated while Bor-Yann Chen worked in National Risk Management Research Laboratory (NRMRL), US Environmental Protection Agency (EPA), Cincinnati, Ohio, U.S.A. under their mentorships.

\section{References}

[1] U. Karra, E. Troop, M. Curtis, S. Karl, N. Patel, B.K. Li, "Performance of plug flow microbial fuel cell (PF-MFC) and complete mixing microbial fuel cell (CM-MFC) for wastewater treatment and power generation," International J. Hydrogen Energy, vol. 38, 2013, pp. 5383 -5388.

[2] L. Zhuang, Y. Zheng, S. G. Zhou, Y. Yuan, H. Yuan, R. Chen, "Scalable microbial fuel cell (MFC) stack for continuous real wastewater treatment," Bioresour. Technol., vol. 106, 2012, pp. 82-88.

[3] B. E. Logan (2008). Microbial fuel cell. New Jersey: John Wiley \& Sons.

[4] F. P. Van der Zee, F. J. Cervantes, "Impact and application of electron shuttles on the redox (bio) transformation of contaminants: A review," Biotechnol. Adv., vol. 27, 2009, pp. 256-277.

[5] K. Watanabe, M. Manefiels, M. Lee, A. Kouzuma, "Electron shuttles in biotechnology," Curr. Opin. Biotechnol., vol. 20, 2009, pp. 633-641.

[6] M. S. Brewer, "Natural Antioxidants: Sources, Compounds, Mechanisms of Action, and Potential Applications," Comprehensive Rev. Food Sci. Food Safety, vol. 10, 2011, pp. 221-247.

[7] H. Karaosmanoglu, P. A. Kilmartin, Chapter 9 "Tea extracts as antioxidants for food preservation," In: Handbook of Antioxidants for Food Preservation, Elsevier Ltd., 2015, pp. 219-233.

[8] J. Sun, Y. Y. Hu, Z. Bi, Y. Q. Cao, "Simultaneous decolorization of azo dye and bioelectricity generation using a microfiltration membrane air-cathode single-chamber microbial fuel cell," Bioresour. Technol., vol. 100, 2009, pp. 3185-3192.

[9] Z. Li, X. Zhang, J. Lin, S. Han, L. Lei, “Azo dye treatment with simultaneous electricity production in an anaerobic-aerobic sequential reactor and microbial fuel cell coupled system," Bioresour. Technol., vol. 101, 2010, pp. 4440-4445

[10] S. A. Patil, S. Gildemyn, D. Pant, K. Zengler, B. E. Logan, K. Rabaey, "A logical data representation framework for electricity-driven bioproduction processes," Biotechnol. Adv., vol. 33, 2015, pp. 736-744.

[11] B. Y. Chen, C. H. Lee, J. S. Chang, C. C. Hsueh, "Impedance fingerprint selection of DHA-producing photoautotrophic microalgae," J. Taiwan Inst. Chem. Engrs., vol. 57, 2015, pp. $36-41$.

[12] K. Solanki, S. Subramanian, S. Basu, "Microbial fuel cells for azo dye treatment with electricity generation: A review," Bioresour. Technol., vol. 131, 2013, pp. 564-571.

[13] J. Sun, W. Li, Y. Li, Y. Hu, Y. Zheng, "Redox mediator enhanced simultaneous decolorization of azo dye and bioelectricity generation in air-cathode microbial fuel cell," Bioresour. Technol., vol. 142, 2013, pp. 407-414.

[14] B. Y. Chen, M. M. Zhang, Y. Ding, C. T. Chang, "Feasibility study of simultaneous bioelectricity generation and dye decolorization using naturally occurring decolorizers," J. Taiwan Inst. Chem. Engrs., vol. 41, 2010, pp. 682-688.

[15] B. Y. Chen, Y. M. Wang, I. S. Ng, S. Q. Liu, J. Y. Hung, "Deciphering simultaneous bioelectricity generation and dye decolorization using Proteus hauseri," J. Biosci. Bioeng., vol. 113, 2012, pp. 502-507.

[16] J. Rau, H. J. Knackmuss, A. Stolz, "Effects of Different Quinoid Redox Mediators on the Anaerobic Reduction of Azo Dyes by Bacteria," Environ. Sci. Technol., vol. 36, 2002, pp. $1497-1504$

[17] B. Y. Chen, C. C. Hsueh, S. Q. Liu, J. Y. Hung, Y. Qiao, P. L. Yueh, Y. M. Wang, "Unveiling characteristics of dye-bearing microbial fuel cells for energy and materials recycling: Redox mediators," International J. Hydrogen Energy, 38, 2013, pp. 15598-15605.

[18] B. Y. Chen, C. C. Hsueh, S. Q. Liu, I. S. Ng, Y. M. Wang, "Deciphering mediating characteristics of decolorized intermediates for reductive decolorization and bioelectricity generation,” Bioresour. Technol., vol. 145, 2013, pp. 321-325.

[19] B. Y. Chen, "Revealing characteristics of mixed consortia for azo dye decolorization: Lotka-Volterra model and game theory," J. Hazard. Materials, vol. 149, 2007, pp. 508-514.

[20] J. A. Field, A. J. M. Stams, M. Kato, G. Schraa, "Enhanced biodegradation of aromatic pollutants in cocultures of anaerobic and aerobic bacterial consortia," Anton Leeuw Int J G, vol. 67, 1995, pp. 47-77.

[21] P. A. Kilmartin, C. F. Hsu, "Characterisation of polyphenols in green, oolong, and black teas, and in coffee, using cyclic voltammetry," Food Chem., vol. 82, 2003, pp. 501-512.

[22] J. A. Field, F. J. Cervantes, "Microbial redox reactions mediated by humus and structurally related quinones," In: Perminova IV, Hatfield K, Hertkorn N, editors. "Use of humic substances to remediate polluted environments: from theory to practice," vol. 52. Dordrecht, The Netherlands: Springer; 2005. pp. 343-52.

[23] D. R. Lovley, J. L. Fraga, J. D. Coates, H. E. L. Blunt, "Humics as an electron donor for anaerobic respiration," Environ. Microbiol., vol. 1, 1999, pp. 89-98.

[24] C. Aranda-Tamaura, M. I. Estrada-Alvarado,A. C. Texier, F. Cuervo, J. Gomez, F. J. Cervantes, "Effects of different quinoid redox mediators on the removal of sulphide and nitrate via denitrification," Chemosphere, vol. 69, 2007, pp. 17221727. 
[25] F. P. Van der Zee, "Anaerobic azo dye reduction," Doctoral Thesis, Wageningen University. Wageningen, The Netherlands, 2002, 142 pages.

[26] B. Y. Chen, C. C. Hsueh, S. Q. Liu, J.Y. Hung, Y. Qiao, P. L. Yueh, Y. M. Wang, "Unveiling characteristics of dye-bearing microbial fuel cells for energy and materials recycling: Redox mediators," International J. Hydrogen Energy, vol. 38, 2013, pp. 15598-15605.

[27] B. Xu, B. Y. Chen, C. C. Hsueh, L. J. Qin, C. T. Chang, "Deciphering characteristics of bicyclic aromatics - mediators for reductive decolorization and bioelectricity generation," Bioresour. Technol., vol. 163, 2014, pp. 280-286.

[28] B. Y. Chen, B. Xu, L. J. Qin, J. C. W. Lan, C. C. Hsueh, "Exploring redox-mediating characteristics of textile dye-bearing microbial fuel cells: thionin and malachite green," Bioresour. Technol., vol. 169, 2014, pp. 277-283.

[29] B. Y. Chen, C. M. Ma, K. Han, P. L. Yueh, L.J. Qin, C. C. Hsueh, "Influence of textile dye and decolorized metabolites on microbial fuel cell-assisted bioremediation," Bioresour. Technol., vol. 200, 2016, pp. 1033-1038.

[30] O. Makhotkina, P. A. Kilmartin, "The use of cyclic voltammetry for wine analysis: Determination of polyphenols and free sulfur dioxide," Analytica Chimica Acta, vol. 668, 2010, pp. 155-165.

[31] M. Przygodzka, D. Zielińska, Z. Ciesarová, K. Kukurová, H. Zieliński, "Comparison of methods for evaluation of the antioxidant capacity and phenolic compounds in common spices," LWT - Food Sci. Technol., vol. 58, 2014, pp. 321-326.

[32] A A. Masek, M. Zaborski, E. Chrzescijanska, "Electrooxidation of flavonoids at platinum electrode studied by cyclic voltammetry," Food Chem., vol. 127, 2011, pp. 699704.

[33] X. Lupea, M. Pop, S. Cracig, "Structure-radical scavenging activity relationahips of flavonoids from Ziziphus and Hydrangea extracts," Rev. Chim., vol. 59, 2008, pp. 309-313. 